\title{
Chapter 5 \\ Interests and Changing Needs from Arms Control, Disarmament, and Non-proliferation for International Security
}

\author{
Robin Grimes
}

Perhaps, before I start my formal comments, I should mention one of the activities I am currently engaged on, particularly relevant to the topic before us.

I chair within the JCPOA framework both the Arak Working Groups and the Arak Technical Experts Groups. Thus, my job, in collaboration with colleagues from China, Russia, France, Germany and the EU Commission, is to help guide the Arak project forward. This is a heavy water moderated and heavy water cooled test reactor. The aim is to keep this reactor away from proliferative uses throughout its design, build and operation. I want to emphasise my personal commitment as well as that of the UK.

So, let me start the formal presentation with some general thoughts concerning the International Rules-Based System and Arms Control, including the role of science.

Without respect for and confidence in, some form of agreed international system of rules and behaviour we will not achieve international security. Change in the approach to the international-rule-based system therefore raises significant concerns.

Nevertheless, renewed emphasis on the international rules-based system is crucial as we need to create an environment reinforced by confidence. This can be supported by rules, transparency and verification, underpinned by evidence and assured processes.

Of course, every party engaged in an arms control process must be confident this activity will not allow a strategic competitor an advantage, or that another party is cheating.

It is critical that all states recognise and respect each other's need for security. Undermining another country's sense of security will only lead to instability. An Arms Control endeavour must be win-win or cheating will be incentivised. The same is true for disarmament.

R. Grimes $(\bowtie)$

Imperial College London, London, UK

e-mail: r.grimes@imperial.ac.uk 
Establishing the common interest, and the possibility of reciprocation are crucial to restoring arms control and discouraging cheating.

To make progress we need: political will; conducive international conditions; and sufficient trust between parties. We therefore need to co-operate!

The broader relations between parties are crucial considerations. If relations remain bad, vulnerabilities could become a major source of danger and potential war.

The Economist quotes Lawrence Freedman as having argued that "Arms Control tends to follow politics_-not lead it." The challenge therefore-if you agree with the premise - is how we develop the political will and political confidence for arms control. Of course, part of that is to have the tools available to carry out the job at hand.

In any case, strategic stability is also our focus and objective rather than arms control alone. But then again, strategic stability is achieved through a combination of arms control, deterrence, non-proliferation and arms reduction measures. So to my mind the argument is somewhat circular.

We also need to consider whether Arms Control in the future should remain single domain, accounting only for nuclear weapons, or whether we need a cross-domain framework that takes into account weapons systems that impact strategic calculations-including new technologies deployed in space and cyber, but also missile defence systems. Looking only slightly further ahead, AI will have a considerable impact across all these.

In general technology developments proceed at pace and we too often play catchup to understand their impact on strategic stability, let alone how to respond within an arms control context.

But the only way we can achieve confidence is through verification, including disarmament verification. There is an international need for increasing co-operation in Verification-whether for disarmament or arms control or any future treaty on fissile materials for nuclear weapons. The most promising area of co-operation is in disarmament verification. This demands co-operation on technology development, especially the application of new science and technology and joint deployment practices.

Let me now turn to the specific issue of Verification-Developing and agreeing effective measures for verifying nuclear disarmament will be vital for enabling the fulfilment of the goals of Article VI of the NPT. Nuclear Weapon States and NonNuclear Weapon States alike will need to have confidence that nuclear-armed states have dismantled all their warheads, and that this has been carried out in a way that makes us safer and does not inadvertently increase the risk of nuclear proliferation.

Beyond the dismantlement of individual warheads, we also need to understand what monitoring and verification procedures may be required across a state's nuclear and defence sites to provide sufficient confidence that nuclear disarmament has taken place irreversibly.

These present significant technological as well as political challenges. And I think human behavioural science has an under-appreciated part of play in helping us think more clearly and broadly about the effectiveness of activities and in measuring their impact. It complements the basic science and engineering. 
Throughout the development of these verification measures, the UK places great importance on involving Non-Nuclear Weapon States and maximising transparency, while upholding our non-proliferation and security commitments.

The UK has continued to play a leading role internationally in the development of nuclear disarmament verification. The UK-Norway Initiative (UKNI), which began in 2007, was the first ever such technical partnership between a Nuclear Weapon State and a Non-Nuclear Weapon State. In 2015, building on UKNI's work, the UK established the Quad Nuclear Verification Partnership with Norway, Sweden and the United States.

In 2017, the Quad undertook the first ever multilateral disarmament verification exercise at RAF Honington. Known as LETTERPRESS, the exercise was held at RAF Honington's former nuclear weapons storage facilities, adding additional realism to the verification activities.

LETTERPRESS provided the opportunity to practice techniques and procedures in a simulated real-world scenario and explored challenges associated with monitoring and verification of declarations, as might be required in future treaties. The exercise was held in strict conformity with the non-proliferation obligations of all participants. The Quad have produced a report for the 2019 NPT Preparatory Committee summarising our work to date and lessons learned.

I think you can see one way in which we begin to explore and learn more about the interplay of technology and behaviour.

The UK has played an active role in the International Partnership for Nuclear Disarmament Verification (IPNDV) since its foundation in 2015. The IPNDV is an initiative that brings together a wide range of countries to identify and solve the challenges associated with nuclear disarmament verification.

As our collaborations on verification have developed, a common theme has been the extent to which Non-Nuclear Weapon States have been able to play a nearcomplete role in the process, while upholding their non-proliferation obligations. This has been possible by viewing the challenge in terms of the verification of nuclear materials and explosives.

The UK is also in the second decade of an active bilateral partnership with the United States in monitoring and verification research. Our joint technical cooperation programme allows us to apply policy, technology and programme expertise to develop and evaluate targeted approaches for transparent reductions and monitoring of: nuclear warheads, fissile material and associated facilities, for potential disarmament and non-proliferation initiatives. Technical experts conduct activities and share information to explore and address essential and difficult monitoring and verification challenges, working to integrate potential approaches for arms control monitoring and transparency.

The UK believes sharing the results of verification initiatives such as the Quad and IPNDV are important for demonstrating transparency, as well as building understanding and capacity for nuclear disarmament verification worldwide.

In parallel to developing verification we need to ensure and assure the nonproliferation of nuclear know-how and materials. This is another key area where 
international co-operation is required - and an area where the UK has been working to enhance measures.

A key part of this narrative is Non-Proliferation-A fundamental corner-stone of global peace and security is our ability to maintain the effective functioning of the global nuclear non-proliferation regime, centred on the enforcement of nuclear safeguards by the IAEA. Without these checks on proliferation, peaceful use of nuclear technology would not be possible.

All countries utilising peaceful nuclear technologies have a duty to finalise safeguards agreements with the IAEA and meet their obligations. The UK is no exception and continues to meet its obligations as a Nuclear Weapons State and responsible user of nuclear energy.

The UK Voluntary Offer Safeguards Agreement with the IAEA and Euratom came into force in 1978. This allows for the application of safeguards on all sources or special fissionable material in facilities or parts of them, subject only to exclusions for reasons of national security. In order to ensure we continue to meet our obligations once Euratom arrangements no longer apply in the UK, we have agreed a new VOA and Additional Protocol with the IAEA, and our new safeguards arrangements are ready.

The UK supports the IAEA's continued efforts to strengthen the international safeguards system across the world, which is an integral part of the global nonproliferation regime within the framework of the NPT. One such element of our support to the IAEA is the UK Safeguards Support Programme (UKSP) which has provided practical assistance to support the strengthening of IAEA safeguards since 1981.

Currently our priorities are to provide training of IAEA inspectors, assistance to enhance the IAEA's safeguards IT infrastructure and participation in the Network of Analytical Laboratories (NWAL). Through NWAL, the UK supports nonproliferation by analysing environmental and bulk samples at the request of the IAEA.

I believe the academic community has a greater role to play here, especially in sharing emerging science across its community, thereby progressing international credibility. Nuclear forensics is an area for which this approach is being effective. At the University of Bristol this summer we initiated a series of international conferences on nuclear forensics, supported by the IAEA. This meeting reviewed the engineering and science behind new and existing techniques. We will hear more about science diplomacy later in the conference but I want just to emphasise the increasing role that academies can play, as evidenced by the conference.

The last topic I will cover is the implementation of Safeguards-The UK believes that a Comprehensive Safeguards Agreement plus an Additional Protocol is the universal verification standard as required by State Parties by the NPT.

The Additional Protocol is an important enhancement to safeguards implementation and the non-proliferation regime. It is a necessary change to ensure that safeguards are fit for the challenges of the twenty first century. Only the Additional Protocol can provide credible assurance of an absence of undeclared nuclear material and activities within a state. 
The UK uses all opportunities to call upon all states that have not yet done so to bring an Additional Protocol into force as soon as possible.

The UK has also supported the evolution of safeguards implementation including through the State Level Concept (SLC). The UK judges that safeguards implementation by the IAEA must continue evolving to address new demands and new challenges incorporating the experience gained from past safeguards implementation and taking advantage of new techniques and technologies.

And the UK has reiterated these points on many occasions, including in the UK's official statements I have personally presented the IAEA General Conference.

The UK supports the IAEA's efforts to improve the efficiency of safeguards. This is vital because the quantities of materials, and number of facilities under safeguards, continues to grow.

Let me finish with these remarks-International co-operation is, of course, key to all of our approaches and endeavours — we need as many nations as possible on-board to make progress, both technologically and politically.

As peaceful nuclear technologies develop, and their use increases, particularly among developing economies, the effective, reliable and sustainable application of safeguards will grow ever more important. This is vital in view of the emergence of small and advanced modular reactors, mobile reactors and, nuclear co-generation as well as the increasing use of radioactive materials in medical, agricultural and scientific research applications.

Maintaining access to the many social, economic and scientific benefits of these technologies requires commitment to the supporting multi-lateral architecture, centred on the NPT and the IAEA, and compliance with obligations and responsibilities by the international community.

In today's uncertain international security environment, we potentially face new strategic technologies such as hypersonic and space-based weapons systems, cyber threats, and all augmented by the application of AI. It is clear there has never been a more important time to work together:

- to rebuild arms control in a manner that creates security and stability for all,

- to create the conditions for disarmament and,

- to implement and strengthen the treaties and measures required for nonproliferation.

Thank you for your attention. 
Open Access This chapter is licensed under the terms of the Creative Commons Attribution 4.0 International License (http://creativecommons.org/licenses/by/4.0/), which permits use, sharing, adaptation, distribution and reproduction in any medium or format, as long as you give appropriate credit to the original author(s) and the source, provide a link to the Creative Commons license and indicate if changes were made.

The images or other third party material in this chapter are included in the chapter's Creative Commons license, unless indicated otherwise in a credit line to the material. If material is not included in the chapter's Creative Commons license and your intended use is not permitted by statutory regulation or exceeds the permitted use, you will need to obtain permission directly from the copyright holder.

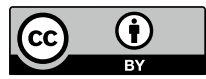

